\title{
Increasing hookah use among adolescent females in the US: analyses from the 2011-2014 National Youth Tobacco Survey (NYTS)
}

\author{
Jenni A. Shearston ${ }^{1,2}$, Su Hyun Park ${ }^{1}$, Lily Lee ${ }^{1,3}$, Chorles Oshinsky ${ }^{I}$, Scott Sherman ${ }^{1}$, Michael Weitzman ${ }^{1}$
}

\begin{abstract}
INTRODUCTION The use of hookah (waterpipe) is increasing rapidly among US adolescents, nearly doubling from2011-2014. Further information is needed about characteristics of those who use hookahs and how key characteristics associated with use may be changing.

METHODS Data from the nationally representative 2014 National Youth Tobacco Survey (NYTS), $\mathrm{n}=22,007$, were analyzed to determine adolescents' characteristics independently associated with use of hookahs, using bivariate and multivariate analyses. Additionally, NYTS 2011-2014 data were analyzed to investigate changes in prevalence of hookah use over time, by sex.

RESULTS Among adolescents in 2014, female sexand past 30-day use of cigarettes or e-cigarettes were each independently associated with higher odds of past 30-day use of hookahs (AOR=1.41, 95\% CI1.15-1.72; AOR=4.01, 95\% CI3.19-5.05; AOR=6.85, 95\% CI 5.29-8.88, respectively). Hispanic adolescents (AOR=1.91, 95\% CI 1.51-2.42) and adolescents who live with someone who uses hookah (AOR=8.56, 95\% CI 6.02-12.18) had greater odds of past 30-day use. From 2011 to 2014 , use among males and females increased, with a percent change of $87 \%$ for males $(1.60 \%$ to $2.99 \%$ ) and $175 \%$ for females ( $1.21 \%$ to $3.33 \%)$.

ConCLusions These data demonstrate the magnitude of adolescent hookah use, particularly among adolescents who use electronic or traditional cigarettes. Most strikingly, rates of female adolescent use have increased much more rapidly than has male use, and adolescent females are for the first time more likely to smoke hookahs than adolescent males in the US nationwide. These findings urgently call for better understanding of the changing correlates of hookah use, including polytobacco use.
\end{abstract}

AFFILIATION
1 New York University (NYU),
School of Medicine, United States
2 New York University (NYU),
Abu Dhabi Public Health Research
Center, United Arab Emirates
3 Brooklyn College, New York,
Brooklyn, United States
coRRESPONDENCE TO
Jenni A. Shearston, New York
University School of Medicine,
227 E 30th St, 7th Floor
Mailroom, 10016 New York,
United States. Email: jenni.
shearston@nyumc.org
KEYwORDS
Hookah,Adolescents, Alternative
tobacco products,Females

AFFILIATION

School of Medicine, United States 2 New York University (NYU),

Abublic Health Research 3 Brooklyn College, New York, Brooklyn, United States

CORRESPONDENCE TO Jenni A. Shearston, New York 227 E 30th St, 7th Floor Mailroom, 10016 New York, United States. Email: jenni. Hookah,Adolescents, Alternative tobacco products, Females

\section{INTRODUCTION}

Although cigarette use globally has declined, particularly among high-income countries ${ }^{1}$, there has been a recent, rapid increase in the use of other forms of tobacco ${ }^{2,3}$. Use of alternative tobacco products, and in particular hookahs (also called waterpipes, hubble-bubble, shisha, narghile), has risen dramatically among adolescents and young adults $\mathrm{s}^{4,5}$. From 2011 to 2014, rates of hookah use among US high school students increased from $4.1 \%$ to $9.4 \%$ while cigarette consumption among the same group decreased from 15.8\% to $9.2 \%$, and overall tobacco use remained fairly level ${ }^{6}$. This finding causes concern that decreases in cigarette use could be offset by increases in use of other tobacco products, such as hookah and electronic cigarettes. A recent article suggests that hookah use may be the next global tobacco epidemic, after the cigarette ${ }^{7}$.

A small but increasing research literature suggests that hookah use may be asaddictive ${ }^{8}$ and more harmful ${ }^{9,10}$ than cigarettes. Hookah smoking has been associated with an increased risk of many diseases, ranging from lung cancer to periodontal disease ${ }^{11}$. The World Health Organization states that one hookah smoking session may be equivalent to inhaling as much smoke as using 5 packs of cigarettes ${ }^{12}$. Despite this, however, hookah is often perceived as a safer and less addictive alternative to cigarettes, especially among young people $^{13,14}$. While some studies have described female gender 
as a protective factor for hookah use among young people ${ }^{15-18}$, other findings have shown no statistically significant differences between male and female use among adolescents ${ }^{1,20}$ and young adults ${ }^{21}$, including an example when female point prevalence was higher than that for males ${ }^{6}$. The Centers for Disease Control and Prevention (CDC) has recently reported rates of past 30-day use of hookahs among adolescents. Of note, point prevalence estimates of hookah use were higher among females than males ( $8.9 \%$ of male vs. $9.8 \%$ of female high school students) $)^{6}$. While tests for statistical significance were not conducted and overlap was reported in the $95 \%$ confidence intervals, these point estimates do raise cause for concern, particularly considering their consistency with other studies. The possibility that these findings may represent a trend of increasing hookah use among adolescent females an outcome with conceivably profound negative public health implications-warrants further investigation.

Using the most recent nationally representative data from the National Youth Tobacco Survey (NYTS) we conducted analyses to address the following two concerns:(1)how have rates of hookah use among adolescent boys and girls in the US changed from 2011 to 2014; and (2) is female gender independently associated with increased rates of hookah use in multivariate analyses that include multiple other adolescent characteristics?

\section{METHODS}

\section{Study Population}

The NYTS is an on-going, school-based cross-sectional survey focusing on tobacco-related indicators, conducted by the CDC. The NYTS uses a stratified, three-stage cluster sample design to provide nationally representative estimates of US students enrolled in grades 6 through 12 in the 50 U.S. States and the District of Columbia. Details of its methodology are available elsewhere ${ }^{22}$. Participants are asked to complete a self-administered questionnaire booklet via pencil and paper. Participation in the NYTS is anonymous and voluntary. Questions about hookah use were introduced in 2011. The CDC's institutional review board (IRB) approved the NYTS data collection protocol, and the dataset was made publically available, making further IRB approval unnecessary.

To investigate whether females are more likely to smoke hookah than males in multivariate analyses, data from the 2014 NYTS were used. To investigate changes in hookah use by gender over time, data were used from each survey conducted between 2011 and 2014. Sample sizes and response rates of each from 2011 to 2014 were 18,866 (72.7\%), 24,658 (73.6\%), 18,406 (67.8\%) and 22,007 (73.3\%), respectively.

\section{Variables}

Hookah Use

Students were asked if they (1) had ever smoked tobacco from a hookah or waterpipeand (2) if they had smoked tobacco from a hookah or waterpipe in the past 30days.Past 30-day use of any tobacco product is frequently used as a proxy measure for current use of that product ${ }^{6,20}$.

\section{Other Voriables}

Demographic variables included sex, age, and ethnicity. Race and ethnicity were classified as non-Hispanic white, nonHispanic black, non-Hispanic Asian and other, or Hispanic. Respondents who reported being non-Hispanic Asian, American Indian, Alaska Native, Native Hawaiian or other Pacific Islander were included in the 'non-Hispanic Asian and other' category.

Use of other forms of tobacco (cigarettes) and nicotine delivery systems (e-cigarettes) were included as covariates. Respondents who selected a response other than "0 days" to the question, "During the past 30 days, on how many days did you use electronic cigarettes or e-cigarettes such as Blu, 21st Century Smoke, or NJOY?" were considered to be past 30-day e-cigarette users. Students who answered other than "0 days" to the question, "During the past 30 days, on how many days did you smoke cigarettes" were considered to be past 30-day cigarette users.

Whether or not students believed that all tobacco products are dangerous was included as a covariate. Students were asked, "How strongly do you agree with the statement, 'all tobacco products are dangerous?" Students who responded "strongly agree" or "agree" were considered to affirm the statement, while those who responded "disagree" or "strongly disagree" were considered to deny the statement.

Living with someone who uses hookah was also included as a covariate. This construct was assessed by asking students if they currently lived with anyone who smoked a range of tobacco products. Students who responded "smoke tobacco from a hookah or waterpipe" were considered living with someone who uses hookah.

\section{Statistical Anolyses}

The NYTS uses a stratified, multistage sample designed to provide nationally representative estimates. Final weights were applied to reflect initial selection probabilities, non-response adjustment, weight trimming, and post-stratification to national student population estimates. All estimates were weighted to account for the complex survey design, except for cell counts in the tables. Prevalence and characteristics of hookah users 


\section{Research Paper}

were stratified by sex. Bivariate analysis was conducted to assess the association of each selected characteristic with the dependent variables. Multivariate logistic regression analysis was performed to obtain the association between hookah use (ever and past 30-day) and sex, adjusting for covariates. All variables included in bivariate analyses were also included in the multivariate model. Covariates included age, ethnicity, past 30-day e-cigarette use, past 30-day cigarette use, believing all tobacco products are dangerous, and living with a hookah smoker. The level of significance for both bivariate and multivariate analyses was set at $\mathrm{p}<0.05$, and all statistical tests were two-tailed. All analyses were conducted using Stata version 11 (StataCorp, College Station, TX).

\section{RESULTS}

The majority of respondents identified as Non-Hispanic white $(58 \%)$, with fairly equivalent proportions of the sample representing each age group. Overall, $14.7 \%$ of adolescents reported lifetime hookah use, and 6.4\%reported use in the past 30days. Substantial proportions of students reported using e-cigarettes or cigarettes in the past 30days (9.3\% and 6.3\%, respectively). Some differences in lifetime and past 30-day hookah use by sex were found. Hispanic girls used hookah more frequently than Hispanic boys. Additionally, among hookah users, girls used e-cigarettes and cigarettes at higher rates than boys across the board.

Further characteristics of adolescents who use hookahs are stratified by sex and shown in Table 1 .

Table 2 displays bivariate and multivariate analyses of ever and past 30-day hookah use by demographic characteristics and other selected covariates. Female sex was associated with increased odds of using hookahs in both models; however findings were only significant in the multivariate analyses (ever use $\mathrm{AOR}=1.17, \mathrm{p}<0.01$; current use $\mathrm{AOR}=1.41, \mathrm{p}<0.001$ ). In bivariate analyses, non-Hispanic Black respondents were associated with decreased odds of using hookahs compared to Non-Hispanic whites (current use $\mathrm{OR}=0.64, \mathrm{p}<0.01$ ) but this finding was not significant in the multivariate model. In contrast, Hispanic individuals were at increased odds of having used hookahs in both forms of analyses (current use $\mathrm{AOR}=1.91, \mathrm{p}<0.001$ ). Additionally, bivariate and multivariate analyses revealed that use of cigarettes (current use AOR $=4.01$,

Figure 1: Prevalence of adolescent past 30 day hookah use by sex from 2011-2014

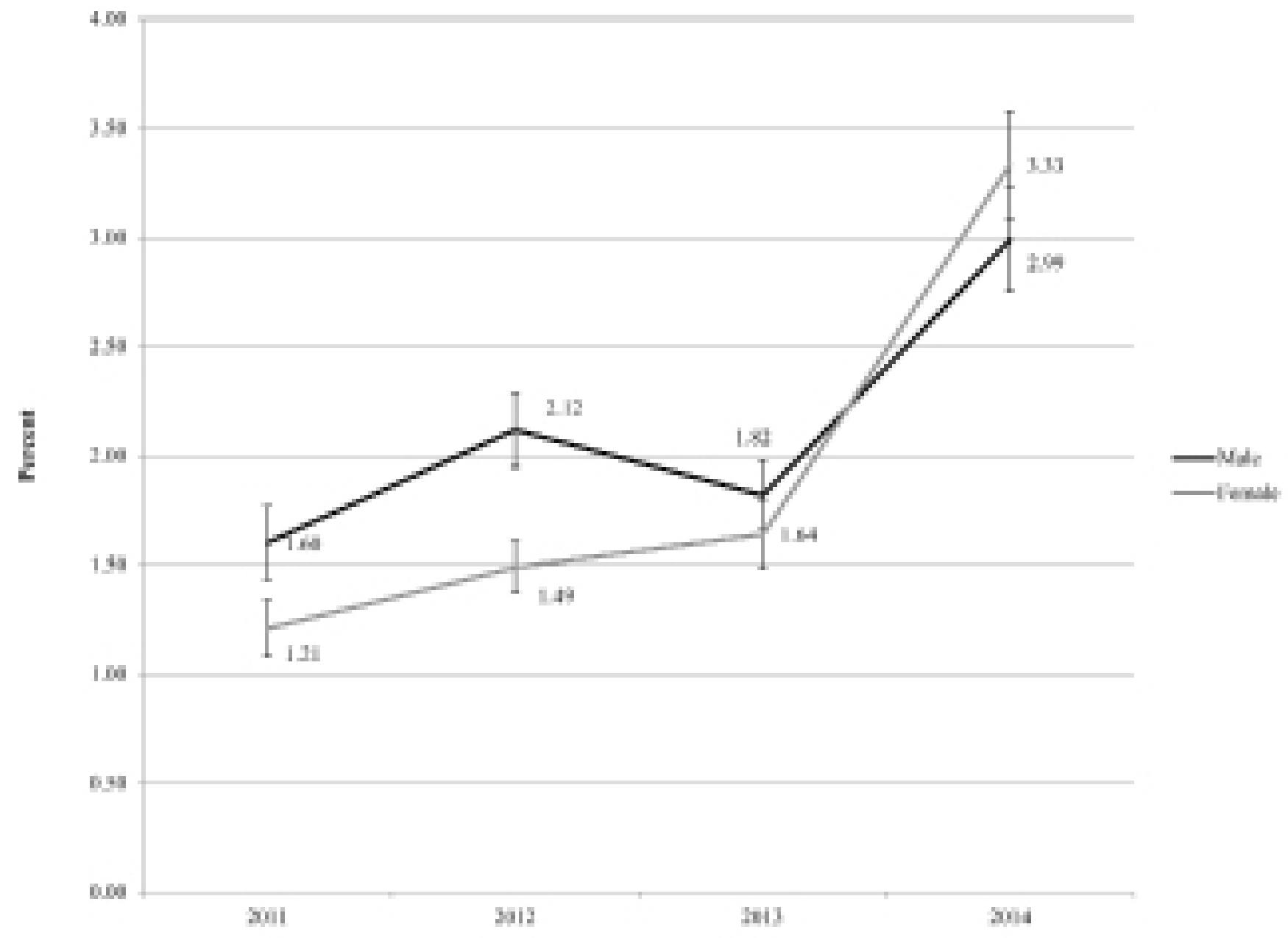




\section{Research Paper}

Figure 2: Percentages of hookah users who are male and female (2011 - 2014)

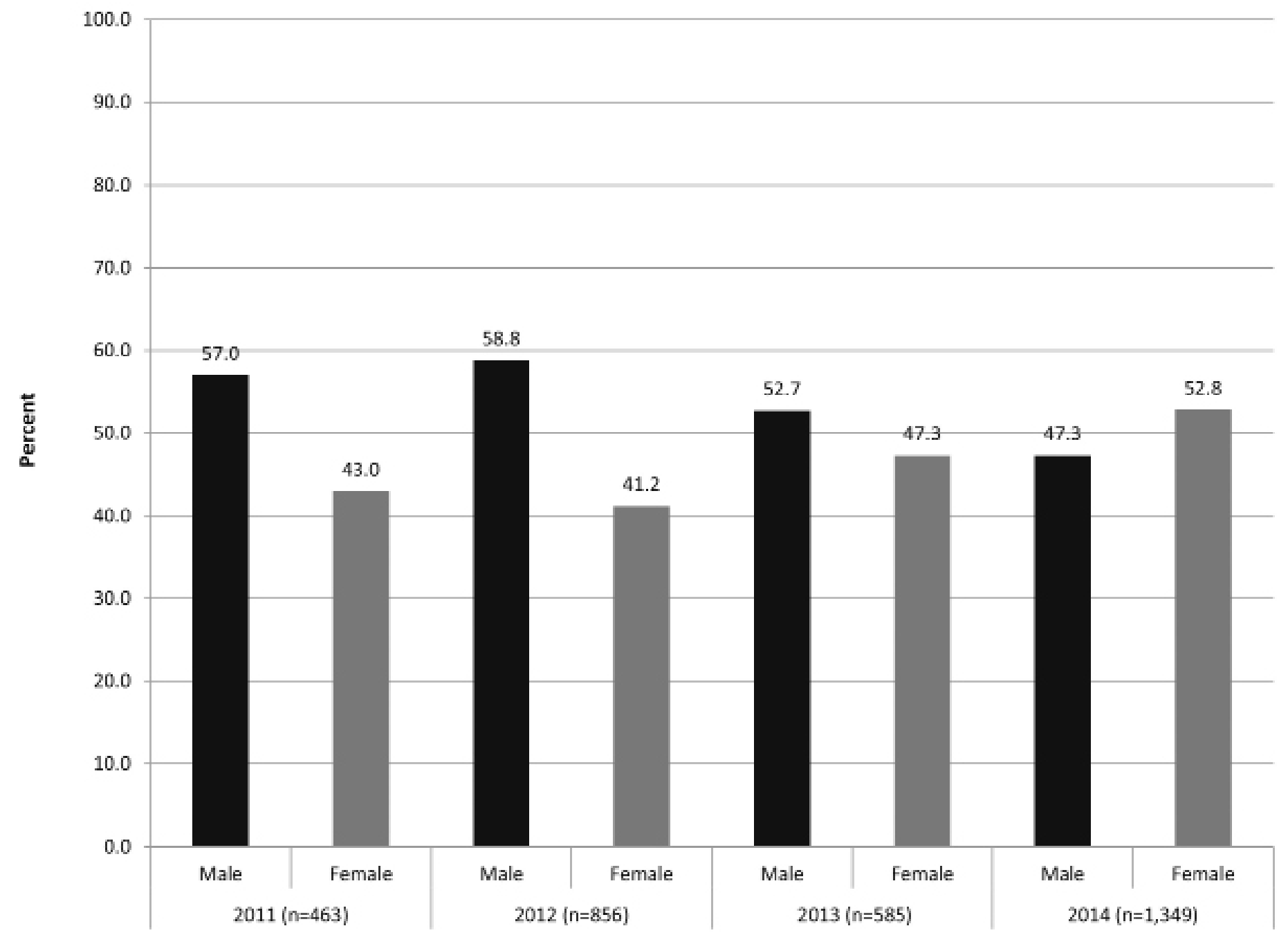

Table 1. Prevalence and Characteristics of US Adolescents Who Use Iookahs, by Sex, NYTS 2014

\begin{tabular}{|c|c|c|c|c|c|c|c|c|c|}
\hline & \multirow{2}{*}{$\begin{array}{l}\text { Total } \\
\% b\end{array}$} & \multicolumn{4}{|c|}{$\begin{array}{l}\text { Ever used hookah } \\
n-2,980\left(11.7^{\circ}\right)^{a}\end{array}$} & \multicolumn{4}{|c|}{$\begin{array}{c}\text { Past } 30 \text { day use of hookah } \\
n=1,319\left(6.1^{\circ}\right)^{a}\end{array}$} \\
\hline & & \multicolumn{2}{|c|}{$\begin{array}{l}\text { Male } \\
o_{o}^{b}\left(95^{\circ} \mathrm{CII}\right)^{b}\end{array}$} & \multicolumn{2}{|c|}{$\begin{array}{c}\text { Female } \\
\%^{b} \quad\left(95^{\circ} \mathrm{CI}\right)^{b}\end{array}$} & \multicolumn{2}{|c|}{$\begin{array}{l}\text { Male } \\
(95 \% \mathrm{CI})^{b}\end{array}$} & \multicolumn{2}{|c|}{$\begin{array}{l}\text { Female } \\
\%_{b}^{b}\left(95^{\circ} \mathrm{CI}\right)^{b}\end{array}$} \\
\hline \multicolumn{10}{|c|}{ Age } \\
\hline$\leq 12$ & 18.7 & 2.3 & $(1.5,3.4)$ & 2.0 & $(1.4,2.8)$ & 1.5 & $(1.0,2.3)$ & 0.9 & $(0.5,1.4)$ \\
\hline 13 & 15.3 & 5.6 & $(4.3,7.1)$ & 8.5 & $(4.8,14.5)$ & 2.6 & $(1.7,4.0)$ & 3.3 & $(2.0,5.4)$ \\
\hline 14 & 14.7 & 8.1 & $(6.5,10.2)$ & 9.8 & $(7.7,12.4)$ & 3.2 & $(2.4,4.4)$ & 4.7 & $(3.4,6.5)$ \\
\hline 15 & 14.9 & 14.2 & $(11.8,17.0)$ & 15.6 & $(12.9,18.8)$ & 7.0 & $(5.5,8.9)$ & 7.9 & $(5.8,10.7)$ \\
\hline 16 & 14.1 & 23.6 & $(21.0,26.4)$ & 22.4 & $(18.4,26.8)$ & 10.1 & $(8.2,12.3)$ & 9.8 & $(7.8,12.2)$ \\
\hline$\geq 17$ & 22.3 & 28.3 & $(25.0,32.0)$ & 28.1 & $(25.0,31.4)$ & 10.3 & $(8.4,12.6)$ & 12.4 & $(9.9,15.5)$ \\
\hline \multicolumn{10}{|c|}{ Race } \\
\hline NH-White & 58.2 & 14.4 & $(12.3,16.7)$ & 14.2 & $(12.2,16.4)$ & 5.8 & $(4.6,7.1)$ & 6.3 & $(5.1,7.7)$ \\
\hline NH-Black & 15.3 & 10.1 & $(8.0,12.6)$ & 10.4 & $(8.2,13.1)$ & 3.6 & $(2.7,4.8)$ & 4.4 & $(2.8,6.7)$ \\
\hline Hispanic & 21.9 & 18.5 & $(16.3,21.0)$ & 20.7 & $(17.8,24.1)$ & 8.7 & $(7.1,10.5)$ & 10.3 & $(8.4,12.4)$ \\
\hline $\mathrm{NH}-\mathrm{Other}{ }^{\mathrm{c}}$ & 4.5 & 9.8 & $(7.2,13.3)$ & 11.9 & $(8.4,16.8)$ & 4.1 & $(2.6,6.3)$ & 4.4 & $(2.8,6.9)$ \\
\hline \multicolumn{10}{|c|}{ Past 30-day use of e-cigs } \\
\hline Yes & 9.3 & 53.7 & $(48.9,58.3)$ & 59.1 & $(52.0,65.9)$ & 31.2 & $(26.1,36.8)$ & 39.6 & $(33.1,46.6)$ \\
\hline
\end{tabular}




\begin{tabular}{|c|c|c|c|c|c|c|c|c|c|}
\hline No & 90.7 & 9.7 & $(8.4,11.3)$ & 10.9 & $(9.3,12.8)$ & 3.1 & $(2.5,3.8)$ & 3.8 & $(3.1,4.7)$ \\
\hline \multicolumn{10}{|c|}{ Past 30-day use of cigarette } \\
\hline Yes & 6.3 & 59.1 & $(53.1,64.9)$ & 61.2 & $(55.1,67.0)$ & 33.6 & $(28.0,39.7)$ & 41.9 & $(35.4,48.6)$ \\
\hline No & 93.7 & 10.5 & $(9.1,12.1)$ & 12.0 & $(10.3,13.9)$ & 3.7 & $(3.1,4.3)$ & 4.6 & $(3.9,5.5)$ \\
\hline \multicolumn{10}{|c|}{ All tobacco are dangerous } \\
\hline Yes & 89.6 & 12.3 & $(10.8,13.9)$ & 13.1 & $(11.4,15.1)$ & 4.6 & $(3.9,5.4)$ & 5.9 & $(4.9,7.0)$ \\
\hline No & 10.4 & 31.5 & $(28.0,35.3)$ & 33.0 & $(27.5,38.9)$ & 16.9 & $(13.8,20.5)$ & 16.1 & $(13.1,19.6)$ \\
\hline \multicolumn{10}{|c|}{ Living with someone who uses hookah } \\
\hline Yes & 3.7 & 61.3 & $(53.2,68.9)$ & 64.1 & $(56.2,71.3)$ & 41.3 & $(30.9,52.6)$ & 36.4 & $(30.2,43.2)$ \\
\hline No & 96.3 & 12.9 & $(11.5,14.5)$ & 12.6 & $(11.1,14.3)$ & 4.9 & $(4.2,5.7)$ & 5.3 & $(4.5,6.3)$ \\
\hline
\end{tabular}

$\mathrm{Cl}=$ confidence interval; $\mathrm{NH}=$ non-Hispanic; aUnweightednfor individuals in each group, with weighted percentages displayed in parentheses. bPercentage estimates and 95\% Confidence Intervals are weighted. cNH-Other includes non-Hispanic Asian, non-Hispanic Asian, American Indian, Alaska Native, Native Hawaiian or other Pacific Islander.

Table 2. Unadjusted and Adjusted Odds of Factors Associated With Ever and Current Use of Hookah Among US Adolescents, NYTS 2014

\begin{tabular}{|c|c|c|c|c|}
\hline & \multicolumn{2}{|c|}{ Ever used hookah } & \multicolumn{2}{|c|}{ Current use of hookah } \\
\hline & $\begin{array}{l}\text { Unadjusted ORs } \\
\qquad(95 \% \mathrm{CI})\end{array}$ & $\begin{array}{l}\text { Adjusted ORs } \\
\text { (95\%CI) }\end{array}$ & $\begin{array}{l}\text { Unadjusted ORs } \\
\qquad(95 \% \text { CI })\end{array}$ & $\begin{array}{l}\text { Adjusted ORs } \\
\text { (95\%CI) }\end{array}$ \\
\hline \multicolumn{5}{|c|}{ Gender } \\
\hline Male & 1.00 & 1.00 & 1.00 & 1.00 \\
\hline Female & $1.04(0.91,1.19)$ & $1.17^{*}(1.03,1.32)$ & $1.13(0.94,1.35)$ & $1.41^{* *}(1.15,1.72)$ \\
\hline \multicolumn{5}{|c|}{ Age } \\
\hline$\leq 12$ & $0.12^{* *}(0.09,0.17)$ & $0.15^{* *}(0.11,0.20)$ & $0.15^{* *}(0.10,0.23)$ & $0.17^{* *}(0.11,0.27)$ \\
\hline 13 & $0.43^{* *}(0.28,0.66)$ & $0.49^{*}(0.32,0.74)$ & $0.38^{* *}(0.25,0.56)$ & $0.47^{* *}(0.31,0.71)$ \\
\hline 14 & $0.56^{* *}(0.44,0.72)$ & $0.62 *(0.46,0.84)$ & $0.52 *(0.36,0.74)$ & $0.58^{*}(0.38,0.89)$ \\
\hline 15 & 1.00 & 1.00 & 1.00 & 1.00 \\
\hline 16 & $1.70^{* *}(1.36,2.13)$ & $1.77^{* *}(1.36,2.31)$ & $1.37^{*}(1.07,1.75)$ & $1.27(0.98,1.64)$ \\
\hline$\geq 17$ & $2.25^{* *}(1.86,2.72)$ & $2.42^{* *}(1.96,2.98)$ & $1.60^{* *}(1.26,2.03)$ & $1.44^{*}(1.10,1.89)$ \\
\hline \multicolumn{5}{|c|}{ Race } \\
\hline NH-White & 1.00 & 1.00 & 1.00 & 1.00 \\
\hline NH-Black & $0.68^{*}(0.53,0.88)$ & $0.81(0.66,1.01)$ & $0.64^{*}(0.44,0.94)$ & $1.01(0.69,1.47)$ \\
\hline Hispanic & $1.48^{* *}(1.27,1.72)$ & $1.74^{* *}(1.47,2.06)$ & $1.65^{* *}(1.34,2.04)$ & $1.91^{* *}(1.51,2.42)$ \\
\hline NH-Othera & $0.74(0.54,1.00)$ & $0.86(0.63,1.17)$ & $0.70(0.49,1.01)$ & $0.78(0.53,1.14)$ \\
\hline Current use of e-cigs & $11.10^{* *}(9.05,13.60)$ & $5.34^{* *}(4.23,6.73)$ & $15.32^{* *}(12.45,18.86)$ & $6.85^{* *}(5.29,8.88)$ \\
\hline Current use of cigarettes & $11.71^{* *}(9.55,14.37)$ & $4.13^{* *}(3.40,5.01)$ & $13.58^{* *}(11.14,16.55)$ & $4.01^{* *}(3.19,5.05)$ \\
\hline All tobacco are dangerous & $0.31 * *(0.26,0.36)$ & $0.49 * *(0.49 \cdot 0.60)$ & $0.28^{* *}(0.24,0.33)$ & $0.51^{* *}(0.41,0.63)$ \\
\hline $\begin{array}{l}\text { Living with someone who } \\
\text { uses hookah }\end{array}$ & $11.65^{* *}(9.0,15.1)$ & $9.72^{* *}(6.98,13.53)$ & $11.76 * *(8.91,15.54)$ & $8.56^{* *}(6.02,12.18)$ \\
\hline
\end{tabular}

$\mathrm{Cl}=$ confidence interval; $\mathrm{NH}=$ non-Hispanic; ${ }^{*} \mathrm{p}<0.01,{ }^{* *} \mathrm{p}<0.001$; aNH-Other includes non-Hispanic Asian, non-Hispanic Asian, American Indian, Alaska Native, Native Hawaiian or other Pacific Islander.

$\mathrm{p}<0.001$ ) and e-cigarettes (current use AOR $=6.85, \mathrm{p}<0.001$ ) were both associated withvery high odds of hookah use. In both models, believing that all tobacco products are dangerous was associated with decreased odds of using hookahs (current use $\mathrm{AOR}=0.51, \mathrm{p}<0.001$ ), while living with a hookah smoker was very strongly associated with increased odds of using hookahs (current use AOR=8.56, $\mathrm{p}<0.001$ ).

Prevalence of adolescent past 30-day hookah use by sex from 2011-2014 are shown in Figure 1. Positive non-linear trends are suggested for both males and females. Prevalence in 
use among boys grew from $1.60 \%$ in 2011 to $2.99 \%$ in 2014 , a percent change of $86 \%$. For girls, a $175 \%$ percent change was observed, growing from $1.21 \%$ in 2011 to $3.33 \%$ in 2014 . Figure 2 displays the percentages of hookah users who are male and female. In 2011, 42.7\% of hookah users were girls, while in 2014 it was $51.9 \%$.

\section{DISCUSSION}

The findings reported in this paper demonstrate the profound increase in hookah use among adolescents. Particularly troubling, however, is the remarkable and unexplaine drapidity of the increase in use by girls, compared to the increase in use by boys, such that adolescent girls are now more likely to use hookahs than are boys in the US. This is true both in point prevalence, as previously reported by the $\mathrm{CDC}^{6}$, as well as in multivariate analyses in this nationally representative sample of our nation's adolescents. This is in marked contrast to findings from the 2011 NYTS and from the 2010-2012 Monitoring the Future surveys, both of which did not find female sex to be independently associated with increased hookah use $\mathrm{s}^{15}$, ${ }^{20}$. Moreover, analyses demonstrate a remarkable disparity in rates of increase between adolescent boys and girls, with an $87 \%$ increase in use among males and a $175 \%$ in females from 2011 to 2014 . The sex-related findings are consistent with the 2015 study by Villanti et al., that found that female use of hookah was higher than male use among young adults aged 18-34 inthe Legacy Young Adult Cohort Study ${ }^{23}$. Thus, two separate recent surveys, one involving adolescents and the other involving young adults,provide similar evidence of increased female use. This merits concern that rates of use among females will continue to grow among both age groups, and certainly calls for continued scrutiny. The etiology or etiologies of this increase are unexplained, and rational policy to stem the tide of increasing use will benefit enormously from understanding what is driving this increased use.

Female sex has previously been associated with increased rates of hookah use outside of the US, although this is rare ${ }^{24}$. Additionally, there is some history of females using cigarettes at higher rates than males, both internationally and domestically. In 2013 approximately 15\% of adult women in Sweden smoked, compared to $13 \%$ of $\operatorname{men}^{25}$. In the US, adolescent females have historically used cigarettes at higher rates than males at different points in time (i.e. the 1990s); and this finding is more prominent among younger adolescents (8th and 10th graders $)^{26}$. However, as students age, trends of boys using cigarettes at higher rates emerge, with 12th grade boys having used at higher rates than females since the late $1980 \mathrm{~s}^{26}$.

The finding that female adolescents now use hookah at higher rates than males, a reversal from the findings of recent years, under scores the importance of frequently re-evaluating the changing landscape of tobacco use in the US. The increase in adolescent female hookah use may serve as a harbinger of resurgence in increased female use of other tobacco products. Research shows that use of one tobacco product correlates with use of other tobacco products ${ }^{27}$, and the history of adolescent female cigarette use shows that female rates have spiked in the past ${ }^{26}$. This finding has implications for health care providers, legislators, and those pushing back against the specific targeting of females by purveyors of tobacco. Tobacco companies have historically targeted and recruited $\mathrm{men}^{28}$, but female focused advertisements have been around for decades ${ }^{28,29}$, and include marketing smoking in women's magazines ${ }^{29}$. Companies produced "light" or "slim" products to target the female population, and advertising correlates with increased use $^{30}$. It is not yet clear why female use of hookahs is increasing. However, it is critical to continue closely monitoring tobacco advertising aimed at youth in general, and females in particular, as an effort to curb this trend.

Also of special note is the remarkable association between hookah and e-cigarette and cigarette use. Our findings show that the odds of using e-cigarettes in the past 30 days are more than four times greater for hookah users, while the odds of using cigarettes in the past 30 days are more than five times greater among hookah users. This is not surprising, as previous analysis of data from the NYTS found that use of one alternative tobacco product is a risk factor for using another, among cigarettes smokers and non-cigarette smokers ${ }^{27}$. Odds ratios for use of various alternative tobacco products as a risk factor for using another type of alternative tobacco product varied from 1.52 (95\% CI 1.12, 2.07) to 60.97 (95\% CI 31.38, $118.45)$ among respondents ${ }^{27}$. Additionally, studies associate e-cigarette use with increased intention to smoke cigarettes, openness to trying cigarettes, and the actual initiation of cigarette smoking ${ }^{31-33}$. However, despite these findings, it should be noted that a significant proportion of US adolescent hookah users in this sample also have never used cigarettes (33.7\%) or e-cigarettes (36\%). These findings elicit concerns that hookah may frequently be a product of first use, or act as a gateway to other tobacco use ${ }^{34,35}$. Clearly, more research is needed to further elucidate the connections between product of initiation, trying multiple products, and future smoking patterns.

Additionally, this analysis found that adolescents who believe all tobacco products are harmful have lower odds of using hookah, and that individuals who live with a person who uses hookah have much higher odds of using themselves, 
compared to those who don't. Both of these findings are consistent with prior literature. An analysis of 2011 NYTS data also revealed that living with someone who uses hookah was associated with increased use ${ }^{20}$. Furthermore, believing that use of hookahis harmful has been associated with increased desire to quit ${ }^{36}$. These findings suggest that interventions might be targeted towards adolescents who are exposed to hookah at home, and that educating adolescents about the harms of hookah may be useful in decreasing use.

This study has several limitations of note. Associationonly, not causation, may be drawn from this cross-sectional data. The study relies on self-reported data. Lack of information regarding detailed demographic characteristics limit investigation of potentially important features of adolescents that might help lead to explicating the causes of this epidemic. Furthermore, the data does not allow elucidation of why adolescent female use is increasing so rapidly. Additionally, NYTS does not survey students who were no longer enrolled in or dropped out of school and requisite information concerning alternative tobacco products only exist for the past several years. Adolescents who use "e-hookah" may misclassify their product use as hookah use, rather than e-cigarette use, potentially leading to misclassification bias. It should also be noted that response options for the measure of hookah use changed between NYTS 2013 and 2014 administrations, when e-cigarettes were removed from the answer options and made into a separate measure, which could have affected the prevalence observed during that period.

\section{CONCLUSION}

The findings in this paper provide important new information in our efforts to prevent increases in the use of this alternative tobacco product. Preventing tobacco use in adolescence saves lives years later and prevents countless other untoward effects on health. To facilitate policy makers and providers in drafting appropriate educational and regulatory interventions, we must define the populations most at risk. This study highlights the increased risk of adolescent hookah use in females, and the increased use of e-cigarette and cigarette use among hookah smokers. The rapid increase in hookah use overall, and among females in particular may portend relative and/or absolute increases in future use of tobacco products in females compared to males. Despite the urgent need for more research, there is sufficient information about the magnitude of use and the negative health consequences of active and passive exposure to hookah smoke to warrant multiple public health interventions, including educational outreach, regulation of hookah and increased funding for further research.

\section{REFERENCES}

1. Samet, J.M.: Tobacco smoking: the leading cause of preventable disease worldwide. Thoracic Surgery Clinics, (2013). 23(2): p. 10312. doi: 10.1016/j.thorsurg.2013.01.009.

2. King, B.A., et al.: Trends in awareness and use of electronic cigarettes among US adults, 2010-2013. Nicotine and Tobacco Research, (2015). 17(2): p. 219-27. doi:10.1093/ntr/ntu191.

3. Centers for Disease Control and Prevention (CDC): Consumption of cigarettes and combustible tobacco--United States, 2000-2011. Morbidity and Mortality Weekly Report, (2012). 61(30): p. 565-9.

4. Lauterstein, D., et al.: The changing face of tobacco use among United States youth. Current Drug Abuse Reviews, (2014). 7(1): p. 29-43.

5. Barnett, T.E., et al.: A multiyear assessment of hookah use prevalence among Florida high school students. Nicotine and Tobacco Research, (2014). 16(3): p. 373-377. doi: 10.1093/ntr/ntt188.

6. Arrazola, R.A., et al.: Tobacco use among middle and high school students-United States, 2011-2014.Morbidity and Mortality Weekly Report, (2015). 64(14): p. 381-5.

7. Maziak, W.: The global epidemic of waterpipe smoking. Addictive Behaviors, (2011). 36(1-2): p. 1-5. doi: 10.1016/j. addbeh.2010.08.030.

8. Cobb, C., et al.: Waterpipe tobacco smoking: an emerging health crisis in the United States. American Journal of Health Behavior, (2010). 34(3): p. 275-85.

9. Eissenberg, T. and A. Shihadeh: Waterpipe tobacco and cigarette smoking: direct comparison of toxicant exposure. American Journal of Preventive Medicine, (2009). 37(6): p. 518-23. doi: 10.1016/j.amepre.2009.07.014.

10. Knishkowy, B. and Y. Amitai: Water-pipe (narghile) smoking: an emerging health risk behavior. Pediatrics, (2005). 116(1): p. e113-9. doi: $10.1542 /$ peds.2004-2173.

11. El-Zaatari, Z.M., H.A. Chami, and G.S. Zaatari: Health effects associated with waterpipe smoking.Tobacco Control, (2015). 24 Suppl 1: p. i31-i43. doi: 10.1136/tobaccocontrol-2014-051908.

12. WHO Study Group on Tobacco Product Regulation. Waterpipe Tobacco Smoking: HealthEffects, Research Needs andRecommended Actions by Regulators, in Tobacco Regulartory Advisory Note. 2005, World Health Organization: Geneva, Switzerland.

13. Noonan, D. and P.A. Kulbok: New tobacco trends: waterpipe (hookah) smoking and implications for healthcare providers. Journal of the American Academy of Nurse Practitioners, (2009). 21(5): p. 258-60. doi: 10.1111/j.1745-7599.2009.00402.x.

14. Primack, B.A., et al.: Prevalence of and associations with waterpipe tobacco smoking among U.S. university students. Annals of Behavioral Medicine, (2008). 36(1): p. 81-6. doi: 10.1007/s12160-008-9047-6.

15. Palamar, J.J., et al.: Hookah use among U.S. high school seniors. Pediatrics, (2014). 134(2): p. 227-34. doi: 10.1542/peds.2014-0538.

16. Rahman, S., et al.: Prevalence, knowledge, and practices of hookah smoking among university students, Florida, 2012. Prev Chronic Dis, (2014). 11: p. doi:10.5888/pcd11.140099.

17. Goodwin, R.D., et al.: Hookah use among college students: prevalence, drug use, and mental health. Drug Alcohol Depend, (2014). 141: p. 16-20. doi:10.1016/j.drugalcdep.2014.04.024.

18. Jarrett, T., et al.: Hookah use among U.S. college students: results from the National College Health Assessment II. Nicotine and Tobacco Research, (2012). 14(10): p. 1145-53. doi:10.1093/ntr/nts003. 
19. Bover Manderski, M.T., M. Hrywna, and C.D. Delnevo: Hookah use among New Jersey youth: associations and changes over time. American Journal of Health Behavior, (2012). 36(5): p. 693-9. doi:10.5993/ajhb.36.5.11.

20. Amrock, S., et al.: Hookah use among adolescents in the United States: results of a national survey. Nicotine and Tobacco Research, (2014). 16(2): p. 231-237. doi: 10.1093/ntr/ntt160.

21. Barnett, T.E., et al.: Evidence of emerging hookah use among university students: a cross-sectional comparison between hookah and cigarette use. BMC Public Health, (2013). 13: p. 302. doi:10.1186/1471-2458-13-302.

22. Office on Smoking and Health. 2014 National Youth Tobacco Survey: Methodology Report. 2015, US Department of Health and Human Services, Centers for Disease Control and Prevention, National Center for Chronic Disease Prevention and Health Promotion, Office on Smoking and Health: Atlanta, GA.

23. Villanti, A.C., et al.: Correlates of Hookah Use and Predictors of Hookah Trial in U.S. Young Adults. American Journal of Preventive Medicine, (2015). 48(6): p. 742-746. doi: 10.1016/j.amepre.2015.01.010.

24. Morton, J., et al.: Cross-country comparison of waterpipe use: nationally representative data from 13 low and middle-income countries from the Global Adult Tobacco Survey (GATS). Tobacco Control, (2014). 23(5): p. 419-27.

doi: 10.1136/tobaccocontrol-2012-050841.

25. Shafey, O., et al., Tobacco Atlas. 3rd ed. 2015: American Cancer Society and World Lung Foundation.

26. Nelson, D.E., et al.: Long-term trends in adolescent and young adult smoking in the United States: metapatterns and implications. American Journal of Public Health, (2008). 98(5): p. 905-15. doi: 10.2105/ajph.2007.115931.

27. Saunders, C. and K. Geletko: Adolescent cigarette smokers' and non cigarette smokers' use of alternative tobacco products. Nicotine and Tobacco Research, (2012). 14(8): p. 977-85. doi: $10.1093 / \mathrm{ntr} / \mathrm{ntr} 323$.

28. National Center for Chronic Disease Prevention and Health Promotion (US) Office on Smoking and Health, Preventing Tobacco Use Among Youth and Young Adults: A Report of the Surgeon General. 2012, Atlanta, Georgia: Centers for Disease Control and Prevention (US).

29. Kaleta, D., B. Usidame, and K. Polanska: Tobacco advertisements targeted on women: creating an awareness among women. Central European Journal of Public Health, (2011). 19(2): p. 73-8.

30. Sieminska, A. and E. Jassem: The many faces of tobacco use among women. Medical Science Monitor, (2014). 20: p. 153-162. doi: $10.1093 / \mathrm{ntr} / \mathrm{ntr} 323$.

31. Bunell, R., I. Agaku, and R. Arrazola: Intentions to smoke cigarettes among never-smoking middle and high school electronic cigarette users: National Youth Tobacco Survey 2011-2013.Nicotine and Tobacco Ressearch, (2015). 17(2): p. 228-35. doi: $10.1093 / \mathrm{ntr} / \mathrm{ntu} 166$.

32. Coleman, B., et al.: Association between electronic cigarette use and openness to cigarette smoking among US young adults.Nicotine and Tobacco Research, (2014): p. 1-7. doi: 10.1093/ntr/ntu211.

33. Primack, B., S. Soneji, and M. Stoolmiller: Progression to traditional cigarette smoking after electronic cigarette use among US adolescents and young adults. JAMA Pedatrics, (2015). 169(11): p. 1018-1023. doi: 10.1001/jamapediatrics.2015.1742.

34. Jensen, P., et al.: Waterpipe use predicts progression to regular cigarette smoking among Danish youth. Substance Use and Misuse, (2010). 45(7-8): p. 1245-1261. doi: 10.3109/10826081003682909.
35. Doran, N., K.M. Godfrey, and M.G. Myers: Hookah Use Predicts Cigarette Smoking Progression Among College Smokers.Nicotine and Tobacco Research, (2015). 17(11): p. 1347-53.

doi: $10.1093 /$ ntr/ntu343.

36. Mays, D., K.P. Tercyak, and I.M. Lipkus: The effects of brief waterpipe tobacco use harm and addiction education messages among young adult waterpipe tobacco users. Nicotine and Tobacco Research, (2016). 18(5): p. 777-84. doi: 10.1093/ntr/ntv223.
CONFLICT OF INTEREST

All the authors have completed and submitted the ICMJE Form for Disclosure of Potential Conflicts of Interest and none were reported.

FUNDING

There was no source of funding for this research.

PROVENANCE AND PEER REVIEW

Not commissioned;

Externally peer reviewed 